1 Mikrobiologisches Institut, Swiss Federal Institute of Technology, $\mathrm{CH}-8092$

Zurich, Switzerland

2 Department of Microbiology, The Ohio State University, Columbus, OH 43210, USA

3 Wadsworth Center, New York State Department of Health, Empire State Plaza, PO Box 509, Albany, NY, USA

\section{Phylogenetic analysis of 18 thermophilic Methanobacterium isolates supports the proposals to create a new genus, Methanothermobacter gen. nov., and to reclassify several isolates in three species, Methanothermobacter thermautotrophicus comb. nov., Methanothermobacter wolfeii comb. nov., and Methanothermobacter marburgensis sp. nov.}

\author{
Alain Wasserfallen, ${ }^{1}$ Jörk Nölling, ${ }^{2}+$ Peter Pfister, ${ }^{1}$ John Reeve ${ }^{2}$ \\ and Everly Conway de Macario ${ }^{3}$
}

Author for correspondence: Alain Wasserfallen. Tel: +41 1632 4488. Fax: +4116321148.
e-mail: wasserfallen@micro.biol.ethz.ch

\begin{abstract}
Using a combination of 165 rRNA analysis and antigenic fingerprinting consisting of new and published data, the phylogenetic position of 18 thermophilic isolates currently classified as Methanobacterium species was reinvestigated. The results were verified by independent methods, including, where applicable, plasmid and phage typing. Comparative analysis of $16 \mathrm{~S}$ rRNA data for 30 strains belonging to the order Methanobacteriales strongly suggested that mesophilic and thermophilic Methanobacterium isolates are distantly related and should be assigned to separate genera. For the thermophilic strains the genus Methanothermobacter was initially proposed by Boone, Whitman and Rouvière. Furthermore, the results support a reclassification of 15 isolates in three species within the proposed genus: (i) Methanothermobacter thermautotrophicus comb. nov., containing eight isolates, six of which are able to utilize formate (type strain $\Delta \mathbf{H}^{\mathrm{T}}$ ); (ii) Methanothermobacter wolfeii comb. nov., containing four formate-utilizing isolates (type strain DSM 2970'); (iii) Methanothermobacter marburgensis sp. nov., containing three obligately autotrophic isolates (type strain Marburg'). of the nine isolates formerly referred to as Methanobacterium thermoformicicum, six were reclassified as Methanothermobacter thermautotrophicus and three as Methanothermobacter wolfeii.
\end{abstract}

Keywords: Archaea, Methanobacterium, Methanothermobacter, phylogeny, 16S rRNA

\section{INTRODUCTION}

Methanogenic archaea share the unique ability to produce methane from a limited number of one- and two-carbon substrates. However, they show a remark-

†Present address: Genome Therapeutics Corp., 100 Beaver Street, Waltham, MA 02154, USA. able diversity based on the sequence of their $16 \mathrm{~S}$ rRNA, a phylogenetic tool that helped define the group (Fox et al., 1977). Additional characteristics typically used to classify methanogens include morphology, nutritional versatility, growth temperature, cell wall structure and $\mathrm{G}+\mathrm{C}$ content of chromosomal DNA (Boone \& Maestrojuan, 1993). Using those criteria, the genus Methanobacterium was defined to include rod-shaped, mesophilic and thermophilic ob- 
ligate autotrophs (growth on $\mathrm{H}_{2} / \mathrm{CO}_{2}$ ), some of which were also capable of utilizing formate for growth. Thermophilic Methanobacterium species are ubiquitous in a number of environments such as anaerobic digesters, digested sludge and hot springs. Up to eight distinct species have been described: Methanobacterium thermoautotrophicum (Zeikus \& Wolfe, 1972; Zeikus, 1972), Methanobacterium wolfei (Winter et al., 1984), Methanobacterium thermoformicicum (Zhilina \& Ilarionov, 1984), Methanobacterium defluvii (Kotelnikova et al., 1993b), Methanobacterium thermophilum (Laurinavichyus et al., 1988), Methanobacterium thermoflexum (Kotelnikova et al., 1993b), Methanobacterium thermoalcaliphilum (Blotevogel et al., 1985) and Methanobacterium thermoaggregans (Blotevogel \& Fischer, 1985).

The need for a taxonomic revision has been recognized for many years by several authors. Based on the results of the Gram stain, Prévot (1980) proposed to separate mesophilic and thermophilic species of Methanobacterium and to rename the thermophiles Zeikusella. DNA-DNA hybridization studies revealed a surprising lack of similarity between two isolates of Methanobacterium thermoautotrophicum, strains $\Delta \mathrm{H}^{\mathrm{T}}$ and Marburg ${ }^{\mathrm{T}}$ (Brandis et al., 1981), a finding later confirmed and extended with antigenic fingerprinting data (Touzel et al., 1992), and eventually corroborated by phylogenetic analysis of $16 \mathrm{~S}$ rRNA sequences (Nölling et al., 1993b). The latter two studies revealed the heterogeneity of two species: Methanobacterium thermoautotrophicum, consisting of obligately autotrophic strains, and Methanobacterium thermoformicicum, consisting of formate utilizers. Three groups were recognized: (i) one containing Methanobacterium thermoautotrophicum $\Delta \mathrm{H}^{\mathrm{T}}$ and Methanobacterium thermoformicicum strains Z-245, FTF, THF, CSM3, FF1 and FF3; (ii) Methanobacterium thermoformicicum strains CB12, SF-4 and HN4; (iii) Methanobacterium thermoautotrophicum Marburg ${ }^{\mathrm{T}}$. Recently, the inability of strain Methanobacterium thermoautotrophicum $\Delta \mathrm{H}^{\mathrm{T}}$ to grow on formate could be traced to the lack of formate-dehydrogenase-encoding genes in its chromosome at the location where those genes are located in Methanobacterium thermoformicicum strain Z-245, while the 'autotroph' Methanobacterium wolfei was found to use formate as a growth substrate (Nölling \& Reeve, 1997). On the other hand, taxonomic reanalysis of Methanobacterium thermoalcaliphilum suggested that it is in fact a synonym of Methanobacterium thermoautotrophicum (Kotelnikova et al., 1993a).

In 1993, Boone, Whitman and Rouvière provided molecular taxonomic evidence that the thermophilic species of Methanobacterium should be moved into a separate genus, suggesting Methanothermobacter as the name (Boone et al., 1993). In the meantime, this new genus name has not been formally proposed or used. A recent survey of the database of 16S rRNA sequences identified several new entries of thermophilic Methanobacterium species, Methanobacterium defluvii,
Methanobacterium thermoflexum (Kotelnikova et al., 1993b), Methanobacterium thermophilum (Laurinavichyus et al., 1988) and Methanobacterium thermoautotrophicum strain ZH3 (Stettler et al., 1994), and prompted us to update the growing body of data available. To complete the survey of available isolates, we also included Methanobacterium wolfei, Methanobacterium thermoautotrophicum strain Hveragerdi and strain Methanobacterium thermoautotrophicum JW510, which are deposited at the German Collection of Microorganisms and Cell Cultures (DSM).

Our analysis relied on three independent data sets: analysis of $16 \mathrm{~S}$ rRNA sequences, antigenic fingerprinting experiments, and data pertaining to extrachromosomal elements (plasmids and phages). Taken together, our results support the two proposals mentioned above, i.e. (i) the need to create a new genus for thermophilic isolates of Methanobacterium, and (ii) a classification of 15 thermophilic isolates into three species.

\section{METHODS}

Archaeal strains and growth conditions. Methanobacterium thermoautotrophicum strains Marburg ${ }^{\mathrm{T}}$ (DSM 2133 ${ }^{\mathrm{T}}$ ) and ZH3 (DSM 9946), Methanobacterium wolfei (DSM 2970 $)$ and Methanobacterium thermoformicicum FF3 (Nölling et al., 1991) were from our respective strain collections. The following strains were obtained from DSMZ: Methanobacterium thermoautotrophicum Hveragerdi (DSM 3590), Methanobacterium thermoautotrophicum JW510 (DSM 1910), Methanobacterium thermoformicicum Z-245 (DSM 3720), Methanobacterium thermoformicicum CB12 (DSM 3664), Methanobacterium defluvii (DSM 7466), Methanobacterium thermophilum (DSM 6529) and Methanobacterium thermoflexum (DSM 7268). Phage $\Psi$ M2 (Jordan et al., 1989; Pfister et al., 1998) was from our strain collection. Strains were grown at $55-60^{\circ} \mathrm{C}$ on a rotary shaker operated at 90 r.p.m. in standard media described for Methanobacterium thermoautotrophicum strain $\Delta \mathrm{H}^{\mathrm{T}}$ (Nölling et al., 1991) and Methanobacterium thermoautotrophicum strain Marburg ${ }^{\mathrm{T}}$ (Schönheit et al., 1979); the latter medium was supplemented with $8 \mu \mathrm{M}$ sodium tungstate and $5 \cdot 8 \mu \mathrm{M}$ sodium selenite.

DNA preparation, amplification and determination of $16 \mathrm{~S}$ rRNA sequences. Chromosomal DNA of Methanobacterium isolates was obtained from a $250 \mathrm{ml}$ culture by the method of Jarrell et al. (1992). After ethanol precipitation, DNA was suspended in a suitable buffer and RNA was removed by digestion for $10 \mathrm{~min}$ at $37^{\circ} \mathrm{C}$ with RNase A. For PCR amplification, 20-50 ng DNA was subjected to a 30-cycle program consisting of $1 \mathrm{~min}$ steps for denaturation $\left(94^{\circ} \mathrm{C}\right)$, annealing $\left(42-45^{\circ} \mathrm{C}\right)$ and amplification $\left(72^{\circ} \mathrm{C}\right)$; the final cycle included a 10 min amplification step. Taq polymerase (Fermentas) and the following oligonucleotides were used (restriction sites underlined): Bam16S, 5'-CACGGATCC GAACGGCTCAGTAACACG-3' and Pst16S, 5'-GTGCTGCAGGGCTACCTTGTTACGACT-3'. Amplified DNA fragments were separated by agarose gel electrophoresis, and the expected $1.4 \mathrm{~kb}$ fragments were excised, isolated, digested with Bam $\mathrm{HI}$ and Pst $\mathrm{I}$, and cloned in the vectors pUC18 (Yanisch-Perron et al., 1985) or pBluescript. rDNA sequences were determined by a chain-termination method with fluorescent detection at Microsynth (Balgach, 
Switzerland). Duplicates were obtained from separate PCR reactions and from different batches of chromosomal DNA to exclude cross-contaminations.

Antigenic fingerprinting. The partial antigenic fingerprint was determined by indirect immunofluorescence and a quantitative slide immunoenzymic assay with a panel of $\mathrm{S}$ probes for rod-shaped methanogens, Methanobrevibacter smithii PS and ALI; Methanobacterium thermoautotrophicum $\mathrm{GCl}$ and $\Delta \mathrm{H}^{\mathrm{T}}$; Methanobacterium bryantii $\mathrm{MoH}$; Methanobacterium formicicum MF; and Methanosphaera stadtmanae MCB3 (Conway de Macario et al., 1982; Macario \& Conway de Macario, 1983, 1985). The cells were cultivated and harvested from $30 \mathrm{ml}$ culture by centrifugation $(10000 \mathrm{~g}, 5 \mathrm{~min})$ at $4{ }^{\circ} \mathrm{C}$, and the pellet was resuspended in $1 \mathrm{ml}$ saline containing $1.5 \%(\mathrm{w} / \mathrm{w})$ formaldehyde and processed for immunological analysis.

Phage typing: infection by phage $\mathbf{T M 2}$. Strains Methanobacterium thermoformicicum FF3 and Methanobacterium thermoautotrophicum $\mathrm{ZH} 3$ pregrown in Marburg medium were diluted $1: 10$ in the same medium, and different volumes of a fresh $\Psi \mathrm{M} 2$ lysate of strain Methanobacterium thermoautotrophicum Marburg ${ }^{\mathrm{T}}$ were added (0.05-1 ml). Before inoculation, the $\Psi$ M2 lysate had been centrifuged at $10000 \mathrm{~g}$ and filtered through a $0.45 \mu \mathrm{m}$ filter to remove intact host cells. A control culture containing no lysate was prepared for both strains. In addition, strain Methanobacterium thermoautotrophicum Marburg ${ }^{\mathrm{T}}$ as a positive lysis control and strain Methanobacterium thermoautotrophicum $\Delta \mathrm{H}^{\mathrm{T}}$ as a negative control were subjected to the same manipulations. All culture vials were pressurized with 2 bar of a $\mathrm{H}_{2} / \mathrm{CO}_{2}$ mixture $(80 / 20 \%, v / v)$ and incubated for up to a week at $55^{\circ} \mathrm{C}$ on a rotary shaker operated at 90 r.p.m.

Presence of chromosomally integrated $\Psi$ M2 sequences. Chromosomal DNA of strains Methanobacterium thermoautotrophicum Marburg ${ }^{\mathrm{T}}$, Methanobacterium thermoautotrophicum ZH3, Methanobacterium thermoautotrophicum $\Delta \mathrm{H}^{\mathrm{T}}$, Methanobacterium thermoformicicum Z-245, Methanobacterium thermoformicicum FF3, Methanobacterium thermoformicicum THF, Methanobacterium wolfei DSM $2970^{\mathrm{T}}$ and Methanobacterium thermoformicicum CB12 were prepared as described above (Jarrell et al., 1992), digested with BamHI, separated by agarose gel electrophoresis in a $0.7 \%$ gel, blotted onto Hybond-N membrane, hybridized with random-primed, DIG-labelled total $\Psi \mathrm{M} 2$ DNA at $68{ }^{\circ} \mathrm{C}$ for $12 \mathrm{~h}$ and subsequently developed according to the manufacturer (Roche Diagnostics).

\section{RESULTS}

\section{Phylogenetic analysis of the 16S rRNA of thermophilic Methanobacterium species}

A total of $1616 \mathrm{~S}$ rRNA sequences of thermophilic Methanobacterium species was found in the GenBank and EMBL databases as of October 12, 1998. In addition to the 11 sequences reported earlier (Nölling et al., 1993b), data are now available for Methanobacterium thermoautotrophicum strain ZH3 (Stettler et al., 1994), Methanobacterium wolfei (Stettler et al., 1995), Methanobacterium defluvii and Methanobacterium thermoflexum (Kotelnikova et al., 1993b) and Methanobacterium thermophilum (Laurinavichyus et al., 1988). However, the available sequence of Methanobacterium wolfei lacks variable region VRI
(Nölling et al., 1993b), and those of Methanobacterium defluvii, Methanobacterium thermoflexum and Methanobacterium thermophilum differ from those of all other isolates at several positions not located in known variable regions. Therefore, we decided to resequence the variable regions of the $16 \mathrm{~S}$ rRNA gene of those four strains; in addition, our survey included two phylogenetically uncharacterized isolates, strains Methanobacterium thermoautotrophicum Hveragerdi (Butsch \& Bachofen, 1981) and Methanobacterium thermoautotrophicum JW510 (DSM 1910), to reach a total of 18 thermophilic isolates. The sequenced portions compared in the alignment of Fig. 1 included bases 101-660 and 1070-1435 according to Ostergaard et al. (1987).

Analysis of partial 16S rRNA sequences suggests that all 18 sequences can be roughly divided into three groups, as proposed earlier (Nölling et al., 1993b): (i) a group of sequences from Methanobacterium thermoautotrophicum strains Marburg ${ }^{\mathrm{T}}, \mathrm{ZH} 3$ and now with a third member, strain Hveragerdi; (ii) a group of sequences from Methanobacterium wolfei and Methanobacterium thermoformicicum strains CB12, SF-4 and HN4; (iii) a group of 11 sequences from the $\Delta \mathrm{H}$ group recognized previously (Nölling et al., 1993b), plus sequences from Methanobacterium defluvii, Methanobacterium thermoflexum, Methanobacterium thermophilum and strain Methanobacterium thermoautotrophicum JW510.

The sequence group around strain Methanobacterium thermoautotrophicum Marburg ${ }^{\mathrm{T}}$ expanded with strain Methanobacterium thermoautotrophicum Hveragerdi, which had, like Methanobacterium thermoautotrophicum strain $\mathrm{ZH} 3$, an additional $\mathrm{C}$ between positions 193 and 194. This prompted us to resequence that portion of the strain Methanobacterium thermoautotrophicum Marburg ${ }^{\mathrm{T}}$ 16S rRNA molecule, and we found no difference at that position (herein referred to as 193b) with strains Methanobacterium thermoautotrophicum Hveragerdi and $\mathrm{ZH} 3$. Because this change was the only difference between the 16S rRNA of strains Methanobacterium thermoautotrophicum Marburg $^{\mathrm{T}}$ and $\mathrm{ZH} 3$, both molecules may now be identical. Eight signature bases were found for the Marburg group of sequences: U122, G167, C193b, G199, G556, U1084, G1085 and U1394 (Fig. 1).

In the Methanobacterium wolfei group, the type strain has a $\mathrm{U}$ at position 901 instead of a $\mathrm{C}$ in strain Methanobacterium thermoautotrophicum Marburg ${ }^{\mathrm{T}}$ and strain Methanobacterium thermoformicicum HN4 has an A at position 1066 instead of a G (Nölling et al., 1993b). Five signature bases were found for this group: A164, A166, C188, C1396 and C1397.

The $\Delta \mathrm{H}$ group now includes four new strains, with strain Methanobacterium thermoautotrophicum JW510 as the closest relative of strain Methanobacterium thermoformicicum THF. Our results indicate that at the 16S rRNA level there is no support for assigning Methanobacterium defluvii, Methanobacterium thermo- 


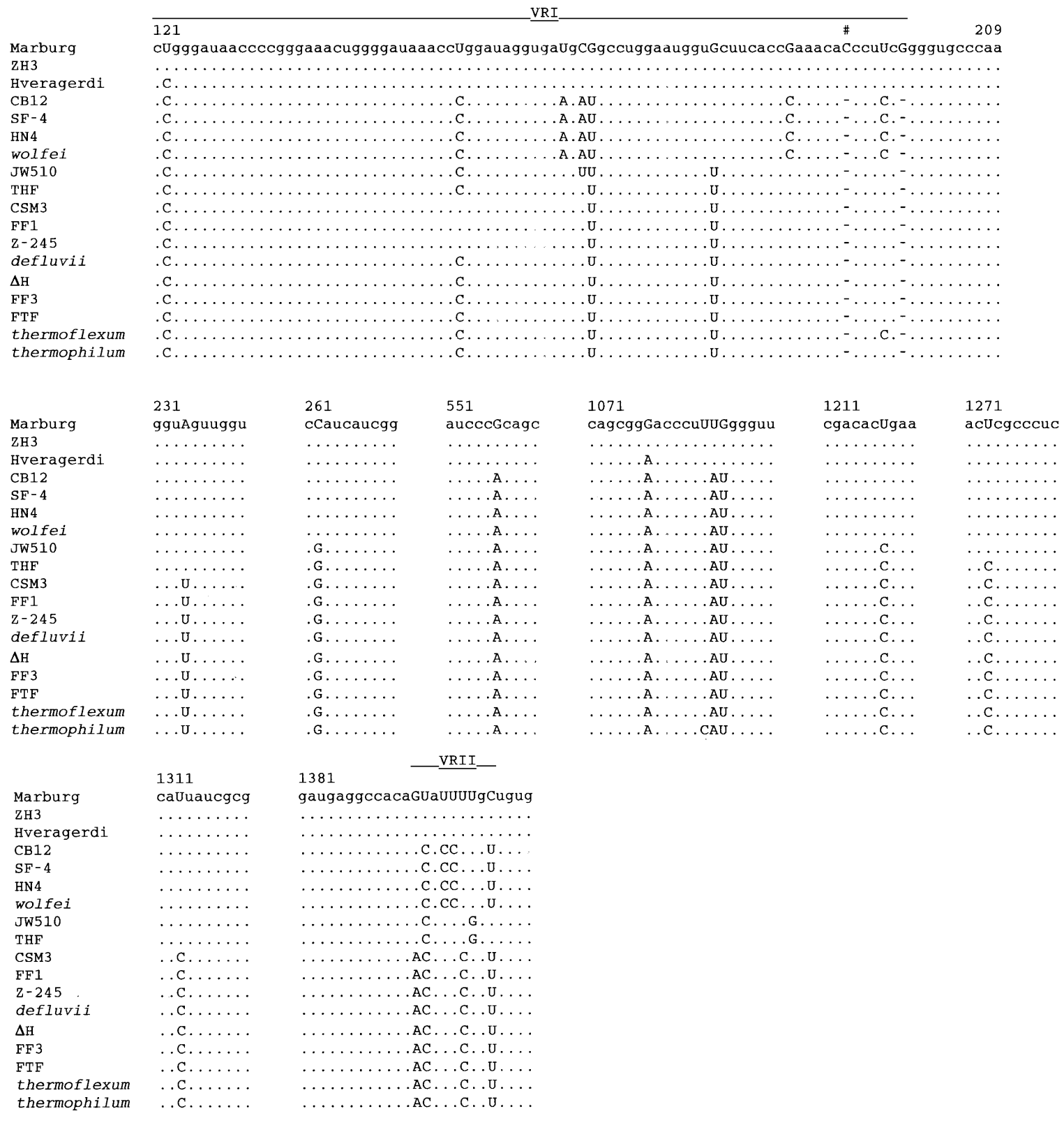

Fig. 1. Alignment of variable regions of $16 \mathrm{~S}$ rRNA sequences from thermophilic Methanobacterium strains. Regions VRI and VRII designate highly variable regions. Nucleotides identical to those in the sequence of strain Methanobacterium thermoautotrophicum Marburg ${ }^{\top}$ are represented by dots, sequence differences by the corresponding nucleotide, and gaps by dashes. An additional nucleotide found upon resequencing strain Methanobacterium thermoautotrophicum Marburg ${ }^{\top} 16 \mathrm{~S}$ rRNA gene is marked by \#. This analysis was performed on two non-contiguous segments of the $16 \mathrm{~S}$ rRNA sequences, corresponding to bases 101-660 and 1070-1435 according to the numbering of Ostergaard et al. (1987); those segments cover variable regions VRI and VRII as well as most of the other positions at which sequence variations have been detected. Sequences were aligned using the program PILEUP (GCG package; gap creation penalty 1.0, gap extension penalty 2.0). Strain names and accession numbers: Methanobacterium thermoautotrophicum Marburg ${ }^{\top}, \mathrm{X}^{15364 ;} \mathrm{ZH} 3$, Z37156; $\Delta \mathrm{H}^{\top}, \mathrm{X} 68720$; Methanobacterium thermoformicicum Z-245, X68712; FTF, X68713; THF, X68711; CSM3, X68716; FF1, X68714; FF3, X68715; CB12, X68717; SF-4, X68718; HN4, X68719.

philum and Methanobacterium thermoflexum to separate species. In our analysis, Methanobacterium thermophilum differed from strain Methanobacterium thermoautotrophicum $\Delta \mathrm{H}^{\mathrm{T}}$ only at bases 308 (A instead of $\mathrm{G}$ ) and 1083 (C instead of $\mathrm{U}$ ), and Methanobacterium thermoflexum only at base 197 (C instead of U), while Methanobacterium defluvii was entirely identical to strain Methanobacterium thermoautotrophicum $\Delta \mathrm{H}^{\mathrm{T}}$ except at three bases unresolved $(\mathrm{N})$ in the Methanobacterium thermoautotrophicum $\Delta \mathrm{H}^{\mathrm{T}}$ sequence. Therefore, we propose to revise their status and incorporate them into the $\Delta \mathrm{H}$ group. Strains 
Methanobacterium thermoformicicum THF and Methanobacterium thermoautotrophicum JW510 stand apart from all other isolates assigned to this group, and their exact phylogenetic position may have to be revised later, should these outlying branches receive new members. Three signature bases were found for the $\Delta \mathrm{H}$ group: U180, G262 and C1217. Strains Methanobacterium thermoformicicum THF and Methanobacterium thermoautotrophicum JW510 considered as a subgroup have only one signature base, G1399, while the $\Delta \mathrm{H}$ group minus $\mathrm{THF}$ and JW510 has five: U234, C1273, C1313, A1393 and C1398.

Similarity values between pairs of 16S rRNA sequences were calculated for all isolates of this study, plus a number of strains belonging to the order Methanobacteriales. In Table 1, they were grouped according to the partitioning suggested by the analysis of $16 \mathrm{~S}$ rRNAs. Two conclusions can be derived from those data: (i) similarity scores within each of the three groups identified by sequence alignment ( $>99 \%$ except for strains Methanobacterium thermoautotrophicum JW510 and Methanobacterium thermoformicicum THF in the $\Delta \mathrm{H}$ group) are significantly higher than scores between any group pair $(97.9 \pm 0.7 \%)$; (ii) similarity scores of all three groups with respect to mesophilic Methanobacterium species are markedly lower $(89 \cdot 9 \pm 0 \cdot 8 \%)$ than any of the above scores, indicating that the three groups around strains Methanobacterium thermoautotrophicum $\Delta \mathrm{H}^{\mathrm{T}}$, Methanobacterium wolfei DSM $2970^{\mathrm{T}}$ and Methanobacterium thermoautotrophicum Marburg ${ }^{\mathrm{T}}$ are more closely related to one another than to mesophilic Methanobacterium species.

Phylogenetic trees constructed with the data in Table 1 are shown in Fig. 2. Both trees are based on partial rRNA sequences ( 927 bases) that were available for all isolates in this study (Fig. 2a) and for other strains of the order Methanobacteriales (Fig. 2b). The latter were used both as outlying sequences and to illustrate the position of thermophiles with respect to mesophiles. As expected since the same data were used, tree A graphically supports the view that thermophilic isolates should be distributed into three species, and tree B illustrates the genus-wide distance separating thermophilic and mesophilic strains of Methanobacterium. Since essentially all the variable positions were included in the sequences analysed here, it is unlikely that the same analysis performed with complete sequences would result in a significantly different picture.

\section{Antigenic fingerprinting}

The antigenic fingerprinting results published previously (Touzel et al., 1992) consistently supported the grouping of thermophilic Methanobacterium strains into three distinct clusters. To complete the survey of antigenic groupings, fingerprinting of representative strains of all three groups was performed, namely strains Methanobacterium wolfei DSM $2970^{\mathrm{T}}$ (a

Table 1. Similarity scores returned by the program FASTA for alignments of $16 \mathrm{~S}$ rRNA sequences of Methanobacteriales according to the proposed three-species model

For this analysis, two non-contiguous segments of the 16S rRNA sequences, corresponding to bases 101-660 and 1070-1435 according to the numbering of Ostergaard et al. (1987), were assembled. In addition to the 18 sequences included in Fig. 1, the following sequences were retrieved (accession no. in parentheses): Methanobacterium bryantii DSM 863 (M59124),

Methanobacterium bryantii RiH2 (AF028688), Methanobacterium formicicum DSM 1312 (M36508), Methanobacterium formicicum FCam (AF028689), Methanobacterium subterraneum A8p (X99044), Methanobacterium subterraneum C2BIS (X99045),

Methanothermus fervidus (M32222), Methanosphaera stadtmanae (M59139), Methanobrevibacter ruminantium, Methanobrevibacter arboriphilicus (both from the Ribosomal Database Project site), Methanobrevibacter filiformis (U82322) and Methanobrevibacter curvatus (U62533).

\begin{tabular}{|c|c|c|c|c|c|c|c|}
\hline & 1 & 2 & 3 & 4 & 5 & 6 & 7 \\
\hline $\begin{array}{l}1 \text { Methanobacterium thermoautotrophicum } \\
\Delta \mathrm{H}^{\mathrm{T}}\end{array}$ & $99 \cdot 4 \pm 0 \cdot 6$ & $98 \cdot 2 \pm 0 \cdot 4$ & $97 \cdot 9 \pm 0 \cdot 6$ & $89 \cdot 9 \pm 0 \cdot 8$ & $87 \pm 2$ & $85 \cdot 4 \pm 0 \cdot 5$ & $87 \cdot 1 \pm 0 \cdot 5$ \\
\hline 2 Methanobacterium wolfei DSM $2970^{\mathrm{T}}$ & & $99 \cdot 8 \pm 0 \cdot 2$ & $97 \cdot 6 \pm 0 \cdot 4$ & $89 \cdot 7 \pm 0 \cdot 6$ & $87 \pm 2$ & $84 \cdot 7 \pm 0 \cdot 3$ & $86 \cdot 9 \pm 0 \cdot 3$ \\
\hline $\begin{array}{l}3 \text { Methanobacterium thermoautotrophicum } \\
\text { Marburg }^{\mathrm{T}}\end{array}$ & & & $99 \cdot 5 \pm 0 \cdot 5$ & $89 \cdot 8 \pm 0 \cdot 6$ & $87 \pm 2$ & $84 \cdot 9 \pm 0 \cdot 2$ & $86 \cdot 9 \pm 0 \cdot 3$ \\
\hline 4 Mesophiles* & & & & $97 \pm 3$ & $89 \pm 2$ & $87 \cdot 1 \pm 0 \cdot 3$ & $83 \cdot 5 \pm 0 \cdot 5$ \\
\hline 5 Methanobrevibacter $\dagger$ & & & & & $95 \pm 5$ & $86 \cdot 0 \pm 1 \cdot 2$ & $81 \cdot 6 \pm 0 \cdot 6$ \\
\hline 6 Methanosphaera stadtmanae & & & & & & 100 & $78 \cdot 9$ \\
\hline 7 Methanothermus fervidus & & & & & & & 100 \\
\hline
\end{tabular}

* Mesophiles refers to Methanobacterium formicicum DSM 1312, Methanobacterium formicicum FCam, Methanobacterium subterraneum, Methanobacterium bryantii DSM 863 and Methanobacterium bryantii RiH2.

$\dagger$ Methanobrevibacter arboriphilicus, Methanobrevibacter ruminantium, Methanobrevibacter filiformis and Methanobrevibacter curvatus. 


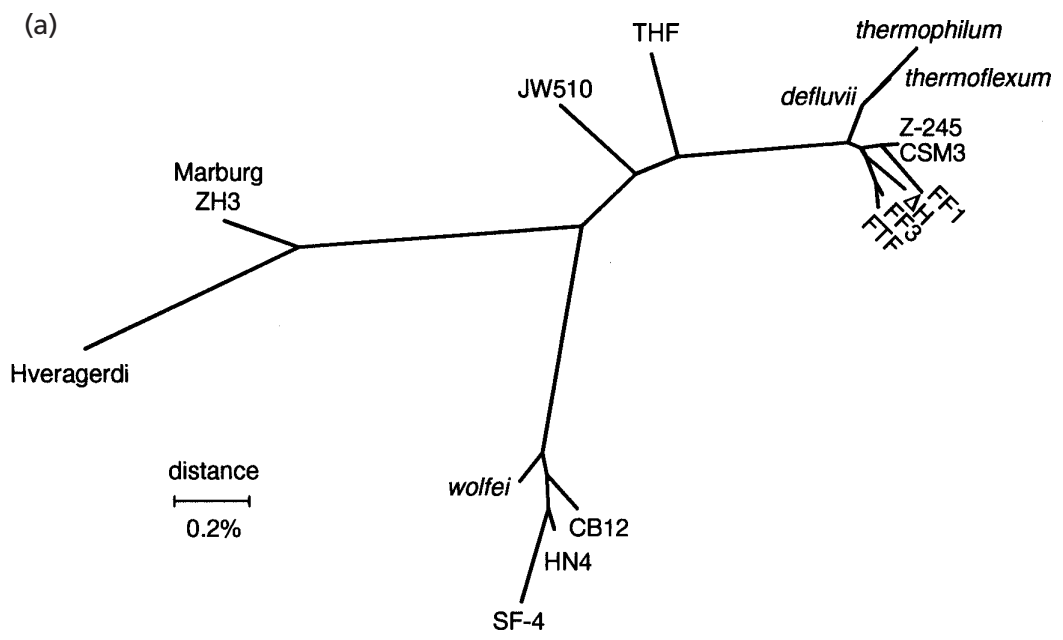

(b)

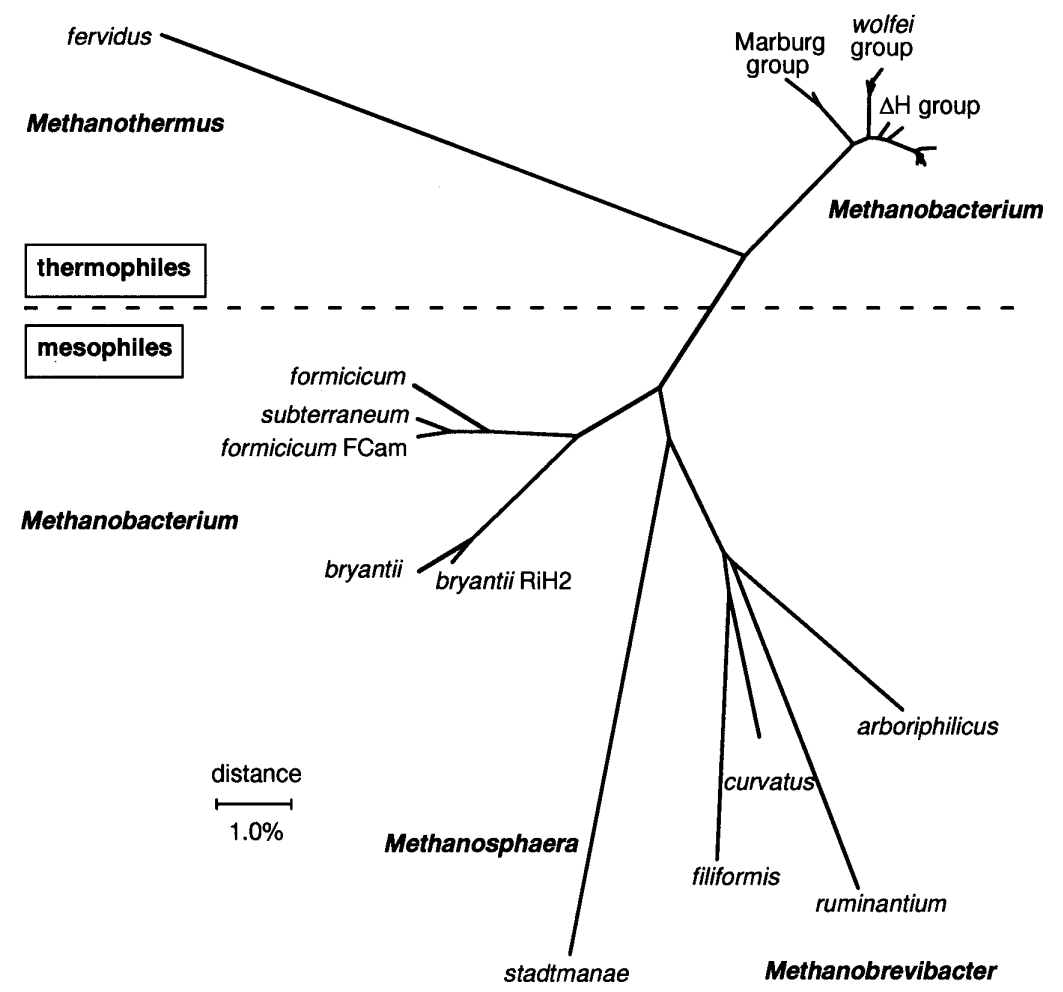

Fig. 2. Phylogenetic trees showing (a) the thermophilic members of the genus Methanobacterium, and (b) their position within the order Methanobacteriales. For this analysis, two non-contiguous segments of the 16S rRNA sequences, corresponding to bases 101-660 and 1070-1435 according to Ostergaard et al. (1987), were assembled and then aligned using the program PILEUP of the GCG package (gap creation penalty 1.0, gap extension penalty 2.0). The alignment was manually corrected to remove extra bases or fill gaps with Ns when those discrepancies were observed only in a minority of the sequences (we observed that unedited sequences confused the programs used to calculate distances). All edited sequences were 927 bases long. Distances were computed with the CLUSTAL W package at the European Bioinformatics Institute (http://www2.ebi.ac.uk/clustalw/) using the neighbour-joining model, and fed to the program DRAWTREE of the PHYLIP package at the Pasteur Institute (http://bioweb.pasteur.fr/ seqanal/interfaces/drawtree-simple.html).

proposed type strain), Methanobacterium thermoautotrophicum JW510, Methanobacterium thermoformicicum FF3, Methanobacterium defluvii, Methanobacterium thermophilum, Methanobacterium thermoflexum and Methanobacterium thermoautotrophicum $\mathrm{ZH} 3$. The strains were antigenically fingerprinted at seven positions using seven S-probes as previously described (Macario \& Conway de Macario, 1983): 1 and 10, Methanobrevibacter smithii PS and ALI, respectively; 2, Methanobacterium formicicum MF; 4, Methanobacterium bryantii $\mathrm{MoH} ; 11$ and 12, Methanobacterium thermoautotrophicum GC1 and $\Delta \mathrm{H}^{\mathrm{T}}$, respectively; and 27, Methanosphaera stadtmanae MCB3. Each strain has a unique antigenic fingerprint that differs from the others including the reference strains (Table 2). None of the strains was antigenically related to the mesophile Methanobacterium formicicum MF in spite of the fact that some, like Methanobacterium thermoformicicum Z245 , grow on formate. Similarly, none was related to the mesophile Methanobacterium bryantii $\mathrm{MoH}$. Methanobacterium defluvii and Methanobacterium thermophilum are antigenically more related to each other than to the other isolates. Except for Methanobacterium thermoautotrophicum Marburg ${ }^{\mathrm{T}}$ and Methanobacterium thermoflexum, all the strains were 
Table 2. Partial antigenic fingerprinting of thermophilic Methanobacterium species analysed and related reference methanogens

The immunizing strains for the antisera were as follows: S-probe 1, Methanobrevibacter smithii PS; S-probe 2, Methanobacterium formicicum MF; S-probe 4, Methanobacterium bryantii $\mathrm{MoH}$; S-probe 10, Methanobrevibacter smithii ALI; S-probe 11, Methanobacterium thermoautotrophicum $\mathrm{GC1}$; S-probe 12, Methanobacterium thermoautotrophicum $\Delta \mathrm{H}^{\mathrm{T}}$; S-probe 27, Methanosphaera stadtmanae MCB3. The intensities of the reactions ranged from 0 [no reaction (values omitted for clarity)] to 4 (maximum intensity).

\begin{tabular}{|c|c|c|c|c|c|c|c|}
\hline \multirow[t]{2}{*}{ Strain } & \multicolumn{7}{|c|}{ Reaction with S-probe } \\
\hline & 1 & 2 & 4 & 10 & 11 & 12 & 27 \\
\hline \multicolumn{8}{|l|}{ Reference } \\
\hline Methanobrevibacter smithii PS & 4 & & & 4 & & & \\
\hline Methanobrevibacter smithii ALI & 3 & & & 4 & & & \\
\hline Methanobacterium thermoautotrophicum GC1 & & & & & 4 & 2 & \\
\hline Methanobacterium thermoautotrophicum $\Delta \mathrm{H}^{\mathrm{T}}$ & & & & & 2 & 4 & \\
\hline Methanobacterium formicicum MF & & 4 & & & & & \\
\hline \multicolumn{8}{|l|}{ Test } \\
\hline Methanobacterium thermoautotrophicum Marburg ${ }^{\mathrm{T}}$ & 1 & & & 3 & & & \\
\hline Methanobacterium thermoautotrophicum ZH3 & & & & & 1 & 1 & \\
\hline Methanobacterium thermoformicicum $\mathrm{CB} 12^{*}$ & & & & & 2 & 1 & \\
\hline Methanobacterium wolfei DSM $2970^{\mathrm{T}}$ & & & & & 3 & & \\
\hline Methanobacterium thermoformicicum $\mathrm{THF}^{*}$ & & & & & 4 & 3 & \\
\hline Methanobacterium thermoautotrophicum JW510 & & & & & 4 & & \\
\hline Methanobacterium thermoformicicum Z-245* & & & & & 3 & 2 & \\
\hline Methanobacterium thermoformicicum FTF* & & & & & 3 & 3 & \\
\hline Methanobacterium thermoformicicum $\mathrm{FF} 3$ & & & & & 4 & 1 & \\
\hline Methanobacterium defluvii & 3 & & & & 4 & 2 & \\
\hline Methanobacterium thermophilum & 4 & & & & 4 & 4 & \\
\hline Methanobacterium thermoflexum & 3 & & & & & & \\
\hline
\end{tabular}

* Data from Touzel et al. (1992).

antigenically related to either Methanobacterium thermoautotrophicum $\mathrm{GC} 1$ or $\Delta \mathrm{H}^{\mathrm{T}}$, or to both. In conclusion, fingerprinting results clearly indicate that mesophilic and thermophilic Methanobacterium isolates are antigenically different. However, among thermophilic isolates they are less informative at the group level, where significant differences are observed (cf. strains Methanobacterium thermoautotrophicum Marburg $^{\mathrm{T}}$ and $\mathrm{ZH} 3$ on the one hand and Methanobacterium thermoautotrophicum $\Delta \mathrm{H}^{\mathrm{T}}$, Methanobacterium defluvii and Methanobacterium thermoflexum on the other hand). The reasons for this antigenic diversity within groups recognized at the $16 \mathrm{~S}$ rRNA level are not clear but may have taxonomic relevance.

\section{Plasmid and phage typing of thermophilic Methanobacterium strains}

Plasmid DNA was reported in three isolates of the $\Delta \mathrm{H} / \mathrm{Z}-245$ group and in two isolates of the Marburg group. In contrast, there is no report about plasmids in the Methanobacterium wolfei group. Interestingly, all three plasmids from the $\Delta \mathrm{H} / \mathrm{Z}-245$ group, $\mathrm{pFV} 1$, $\mathrm{pFZ1}$ and $\mathrm{pFZ2}$, are structurally related, suggesting that they share a common replicon, pFZ1 (Nölling et al., 1991, 1992). Similarly, the DNA sequences of plasmids pME2001 and pME2200 from strains Methanobacterium thermoautotrophicum Marburg ${ }^{\mathrm{T}}$ and $\mathrm{ZH} 3$, respectively, reveal a close evolutionary relationship with each other (Stettler et al., 1994), but not with the pFZ1 plasmid family (data not shown). Consistent with the existence of two types of replicon in Methanobacterium, portions of plasmids $\mathrm{pFV} 1$ and $\mathrm{pFZ1}$ were detected by Southern hybridization in total DNA of plasmid-free strains Methanobacterium thermoautotrophicum $\Delta \mathrm{H}^{\mathrm{T}}$, Methanobacterium thermoformicicum THF, Methanobacterium thermoformicicum FF1, Methanobacterium thermoformicicum FF3 and CSM3 belonging to the $\Delta \mathrm{H} / \mathrm{Z}-245$ group, but not in the DNA of strains Methanobacterium thermoformicicum CB12 and SF-4 belonging to the Methanobacterium wolfei group or in the DNA of strain Methanobacterium thermoautotrophicum Marburg ${ }^{\mathrm{T}}$. Strain Methanobacterium thermoformicicum $\mathrm{HN} 4$ of the Methanobacterium wolfei group was the only isolate giving a hybridization signal with one of the probes (Nölling et 
Table 3. Main phenotypic traits of type strains of thermophilic Methanobacterium isolates

Sources: Methanobacterium thermoautotrophicum $\Delta \mathrm{H}^{\mathrm{T}}$, Zeikus \& Wolfe (1972);

Methanobacterium thermoautotrophicum Marburg ${ }^{\mathrm{T}}$, Schönheit et al. (1980); Methanobacterium wolfei DSM $2970^{\mathrm{T}}$, Winter et al. (1984).

\begin{tabular}{|c|c|c|c|}
\hline & $\Delta \mathbf{H}^{\mathrm{T}}$ & Marburg $^{T}$ & DSM 2970 ${ }^{T}$ \\
\hline Source & Sewage sludge & Sewage sludge & $\begin{array}{c}\text { Sewage sludge and } \\
\text { river sediment }\end{array}$ \\
\hline Morphology & $0.4 \times 3-120 \mu \mathrm{m}$ & $0 \cdot 35 \times 3-20 \mu \mathrm{m}$ & $0.4 \times 2.5 \mu \mathrm{m}$ \\
\hline Growth substrates & $\mathrm{H}_{2} / \mathrm{CO}_{2}{ }^{*}$ & $\mathrm{H}_{2} / \mathrm{CO}_{2}$ & $\mathrm{H}_{2} / \mathrm{CO}_{2}$, formate* \\
\hline \multicolumn{4}{|l|}{ Temperature } \\
\hline Range & $40-75^{\circ} \mathrm{C}$ & $45-70{ }^{\circ} \mathrm{C}$ & $37-74{ }^{\circ} \mathrm{C}$ \\
\hline Optimum & $65-70^{\circ} \mathrm{C}$ & $65^{\circ} \mathrm{C}$ & $55-65^{\circ} \mathrm{C}$ \\
\hline \multicolumn{4}{|l|}{$\mathrm{pH}$} \\
\hline Range & $6 \cdot 0-8 \cdot 8$ & $5 \cdot 0-8 \cdot 0$ & $6 \cdot 0-8 \cdot 2$ \\
\hline Optimum & $7 \cdot 2-7 \cdot 6$ & $6 \cdot 8-7 \cdot 4$ & $7 \cdot 0-7 \cdot 5$ \\
\hline \multicolumn{4}{|l|}{$\mathrm{NaCl}$ concn $\left(\mathrm{g} \mathrm{l}^{-1}\right)$} \\
\hline Range & $0 \cdot 1-35 \dagger$ & $0 \cdot 1-35 \dagger$ & $\mathrm{NA} \dagger$ \\
\hline Optimum & $0 \cdot 6 \dagger$ & $0.5 \dagger$ & Up to 10 \\
\hline $\mathrm{G}+\mathrm{C} \mathrm{mol} \%$ & $50 \pm 2 \%$ & $48 \pm 0 \cdot 5 \%$ & $61 \S$ \\
\hline
\end{tabular}

* Formate can be used as growth substrate by most of the isolates phenotypically closely related to the type strain $\Delta \mathrm{H}^{\mathrm{T}}$; unlike earlier reports, Methanobacterium wolfei grows on formate (J. Nölling, unpublished data).

$\uparrow$ Data from Ciulla et al. (1994) and Perski et al. (1981); NA, data not available.

+ Additional data from Brandis et al. (1981); Kotelnikova et al. (1993a); Touzel et al. (1992).

$\S 48.5 \mathrm{~mol} \%$ in Kotelnikova et al. (1993a).

al., 1993c). However, in the absence of a transformation system for those thermophiles, it is not possible to infer whether plasmids carrying the pFV1 replicon cannot replicate in hosts harbouring plasmids of the pME2001 family and vice versa.

Phage $\Phi F 1$ specifically infects the following strains of the $\Delta \mathrm{H} / \mathrm{Z}-245$ group: Methanobacterium thermoautotrophicum $\Delta \mathrm{H}^{\mathrm{T}}$, Methanobacterium thermoformicicum strains Z-245, FTF, CSM3, FF1 and FF3 (but not THF). In contrast, Methanobacterium thermoformicicum strains CB12, SF-4 and HN4 of the Methanobacterium wolfei group and strain Methanobacterium thermoautotrophicum Marburg ${ }^{\mathrm{T}}$ were not infected (Nölling et al., 1993a). Conversely, phage YM2, which is specific for strain Methanobacterium thermoautotrophicum Marburg ${ }^{\mathrm{T}}$, did not infect strains Methanobacterium thermoautotrophicum $\Delta \mathrm{H}^{\mathrm{T}}$, Methanobacterium thermoformicicum Z-245, Methanobacterium thermoformicicum THF and Methanobacterium thermoformicicum $\mathrm{FF} 3(\Delta \mathrm{H} / \mathrm{Z}-245$ group), Methanobacterium thermoformicicum $\mathrm{CB} 12$ and Methanobacterium wolfei DSM $2970^{\mathrm{T}}$ (Methanobacterium wolfei group) and Methanobacterium thermoautotrophicum ZH3 (Marburg group). It has been shown that strain Methanobacterium thermoformicicum THF harbours a restriction/modification system with target sites on the genome of $\Phi F 1$, thus possibly explaining the phage-resistant phenotype of strain Methanobacterium thermoformicicum THF (Nölling et al., 1993a). A similar reasoning can be made to explain the failure of phage $\Psi \mathrm{M} 2$ to infect cells of strain Methanobacterium thermoformicicum THF since the complete phage sequence is now available (Pfister et al., 1998). The resistance of Methanobacterium thermoautotrophicum strain $\mathrm{ZH} 3$ to infection by phage $\Psi \mathrm{M} 2$ may be due to inefficient phage binding related to differences in the cell surface properties of strains Methanobacterium thermoautotrophicum $\mathrm{ZH} 3$ and Methanobacterium thermoautotrophicum Marburg ${ }^{\mathrm{T}}$, as indicated by the antigenic fingerprinting results. Methanobacterium wolfei spontaneously lyses when starved for hydrogen (König et al., 1985) and harbours an integrated, defective prophage (Stettler et al., 1995). Thus, the host range of phages of the $\Psi \mathrm{M}$ family may not be limited to isolates of the Marburg group, although no productive infection has yet been documented in any isolate other than strain Methanobacterium thermoautotrophicum Marburg ${ }^{\mathrm{T}}$ itself.

Plasmid content and phage susceptibility are somewhat relative phenotypes due to frequent exceptions. However, our data suggest the existence of distinct plasmid and phage families in accordance with the proposed speciation model.

\section{DISCUSSION}

The genus Methanothermobacter was recently proposed to include several, if not all, thermophilic 
strains of Methanobacterium (Boone et al., 1993). This proposal was based on analysis of partial 16S rRNA sequences, which returned less than 93-95\% similarity with their mesophilic counterparts. Our own results, summarized in Table 1 and Fig. 2, confirm that view, and our similarity scores of approximately $90 \%$ undoubtedly support the creation of a new genus, Methanothermobacter. In addition, they indicate a certain level of discrepancy among thermophilic isolates, which led us to propose the creation of three species with type strains $\Delta \mathrm{H}^{\mathrm{T}}$, DSM $2970^{\mathrm{T}}$ and Marburg $^{\mathrm{T}}$, respectively (Table 3; see also Touzel et al., 1992). To some extent, this model is supported by antigenic fingerprints, and plasmid as well as phage typing. However, those markers are not necessarily distinctive phenotypes in methanogens (see, for example, Keswani et al., 1996) and those three species are difficult to define using growth characteristics and habitats, for example. Isolates grouped together with strain Marburg ${ }^{\mathrm{T}}$ on the basis of their 16S rRNA signatures grow as straight to smoothly curved rods in chains significantly shorter than those formed by cells of isolates of the $\Delta \mathrm{H}$ group.

DNA-DNA reassociation experiments performed by several groups also clearly indicate phenotypic differences between strain Methanobacterium thermoautotrophicum $\Delta \mathrm{H}^{\mathrm{T}}$, strain Methanobacterium wolfei DSM $2970^{\mathrm{T}}$ and strain Methanobacterium thermoautotrophicum Marburg ${ }^{\mathrm{T}}$ (Brandis et al., 1981; Kotelnikova et al., 1993a; Touzel et al., 1992). This is strong evidence in support of our proposal for a new species with strain Marburg ${ }^{\mathrm{T}}$ as a type strain. However, using in part the same phenotype, Kotelnikova et al. (1993a, b) recently described three new thermophilic species, Methanobacterium defluvii, Methanobacterium thermoflexum and Methanobacterium thermophilum. In contrast, our analysis of $16 \mathrm{~S}$ rRNA indicates a very close relationship of those three strains with isolates of the $\Delta \mathrm{H}$ group. In keeping with the conclusions of Stackebrandt \& Goebel (1994), we therefore propose to transfer those three thermophilic strains to the genus Methanothermobacter while keeping their status as separate species, viz. as Methanothermobacter defluvii, Methanothermobacter thermoflexus and Methanothermobacter thermophilus.

\section{Description of Methanothermobacter gen. nov. (David R. Boone, personal communication)}

Methanothermobacter (Me.tha.no.ther.mo.bac'ter. N.L. neut. n. methanum methane; Gr. adj. thermos hot; M.L. masc. n. bacter equivalent of Gr. dim. neut. n. bakterion rod, staff; M.L. masc. n. Methanothermobacter thermophilic methane rod).

Curved or crooked slender rods, moderately long to filamentous, $0 \cdot 3-0 \cdot 5 \mu \mathrm{m}$ wide. Endospores not formed. Cells stain Gram-positive, and ultrastructure appears typically Gram-positive, but cell walls are composed of pseudomurein. Non-motile. Cells produce fimbriae. Very strictly anaerobic. Fastest growth between 55 and $65^{\circ} \mathrm{C}$. Energy metabolism by reduction of $\mathrm{CO}_{2}$ to $\mathrm{CH}_{4}$, with $\mathrm{H}_{2}$ as electron donor; some cells can also use formate as electron donor. Sulfur is reduced to sulfide, but this reaction does not yield energy for growth. Ammonia is the sole nitrogen source, and sulfide may serve as sulfur source. The DNA $\mathrm{G}+\mathrm{C}$ content is 32-61 mol\%. Type species: Methanothermobacter thermautotrophicus comb. nov.

\section{Emended description of Methanothermobacter thermautotrophicus comb. nov. [formerly Methanobacterium thermoautotrophicum (corrig.) Zeikus and Wolfe 1972, 712 ${ }^{\mathrm{AL}}$ ]}

Methanothermobacter thermautotrophicus (therm.au. to.tro.phi'cus. Gr. adj. thermos hot; Gr. pref. auto self; Gr. adj. trophikos one who feeds; N.L. masc. adj. thermautotrophicus thermophilic and autotrophic).

Cells are slender, cylindrical, irregularly crooked rods that are $0.35-0.5 \mu \mathrm{m}$ wide and $3-7 \mu \mathrm{m}$ long and frequently occur in filaments that are $10-120 \mu \mathrm{m}$ long. Gram-positive. Non-motile. Endospores not formed. Deep colonies in roll tubes are tannish white, roughly spherical, diffuse and filamentous. Growth is rapid in mineral medium with $\mathrm{CO}_{2}$ as the sole carbon source, $\mathrm{NH}_{3}$ as the sole nitrogen source, sulfide as the sole sulfur source and $\mathrm{H}_{2} / \mathrm{CO}_{2}$ as the sole energy source. Growth on formate as the sole carbon and energy source is possible for some strains. Not stimulated by organic additions, although acetate may be assimilated. The DNA $\mathrm{G}+\mathrm{C}$ content is $48-50 \mathrm{~mol} \%$ as determined by thermal denaturation. Some strains harbour a plasmid, and some are infected by lytic phages. Habitat: thermophilic, anaerobic digesters, hot springs. The type strain is strain $\Delta \mathrm{H}^{\mathrm{T}}$ (=DSM $1053^{\mathrm{T}}=$ ATCC $29096^{\mathrm{T}}$ ), which was isolated from an anaerobic sewage sludge digester; this strain does not grow on formate. The reference strain includes strain Z-245 (= DSM 3720) Zhilina and Ilarionov 1984, which grows on formate.

\section{Emended description of Methanothermobacter wolfeii comb. nov. (formerly Methanobacterium wolfei Winter and Lerp 1984, 465 $5^{\mathrm{AL}}$ )}

Methanothermobacter wolfeii (wolf'e.i.i. M.L. gen. n. wolfeii of Wolfe who pioneered the research on methanogenesis).

Cells are slender, cylindrical, sometimes crooked rods that are $0.35-0.5 \mu \mathrm{m}$ wide and $2.5 \mu \mathrm{m}$ long and occur singly or in pairs, or in longer chains. Gram-positive. Non-motile. Endospores not formed. Colonies on agar plates are 1-2 $\mathrm{mm}$ in diameter, yellowish and convex. Growth is rapid in mineral medium with $\mathrm{NH}_{3}$ as the sole nitrogen source, sulfide as the sole sulfur source and $\mathrm{H}_{2} / \mathrm{CO}_{2}$ or formate as the sole carbon and energy sources. The type strain is stimulated by addition of tungsten and spontaneously lyses when deprived of energy. The DNA $\mathrm{G}+\mathrm{C}$ content of the type strain is $61 \mathrm{~mol} \%$ as determined by thermal denaturation. 
Strains are devoid of extrachromosomal elements. The type strain harbours a chromosomally integrated, defective prophage. Habitat: mesophilic and thermophilic sludge or digesters. The type strain is strain DSM $2970^{\mathrm{T}}$ (=ATCC $43096^{\mathrm{T}}$ ), which was isolated from a mixture of sewage sludge and river sediment.

\section{Description of Methanothermobacter marburgensis sp. nov. (formerly Methanobacterium thermoautotrophicum)}

Methanothermobacter marburgensis (mar.bur.gen'sis. German n. Marburg name of a city in Germany; M.L. masc. suffix -ensis pertaining to/originating from a locality; M.L. n. marburgensis from Marburg).

Cells are slender, cylindrical rods that are $0 \cdot 30-0 \cdot 4 \mu \mathrm{m}$ wide and $3 \cdot 0-3.5 \mu \mathrm{m}$ long and frequently occur in pairs or chains up to $20 \mu \mathrm{m}$ long. Gram-positive. Nonmotile. Endospores not formed. Colonies on agar plates are $1-4 \mathrm{~mm}$ in diameter, white or slightly yellowish, and convex. Growth is rapid in mineral medium with $\mathrm{CO}_{2}$ as the sole carbon source, $\mathrm{NH}_{3}$ as the sole nitrogen source, sulfide as the sole sulfur source and $\mathrm{H}_{2} / \mathrm{CO}_{2}$ as the sole energy source. Growth on formate is not possible. Not stimulated by organic additions, although acetate may be assimilated. The DNA $\mathrm{G}+\mathrm{C}$ content of the type strain is $48 \mathrm{~mol} \%$ as determined by thermal denaturation. Strains may harbour one plasmid, and the type strain is infected by lytic phages. Habitat: mesophilic sewage sludge and hot springs. The type strain is strain Marburg ${ }^{\mathrm{T}}(=$ DSM $2133^{\mathrm{T}}$ ), which was isolated from mesophilic sewage sludge.

\section{ACKNOWLEDGEMENTS}

We thank Alberto J. L. Macario for his input in the antigenic fingerprinting work, David Boone for communicating in advance the description of the genus Methanothermobacter and Sandra Ragettli for excellent technical assistance. This work was supported by grant 31-45571.95 of the Swiss NSF to A. W. and Department of Energy grant DE-FGO@87ER13731 to J.N.R.

\section{REFERENCES}

Blotevogel, K.-H. \& Fischer, U. (1985). Isolation and characterization of a new thermophilic and autotrophic methaneproducing bacterium: Methanobacterium thermoaggregans sp. nov. Arch Microbiol 142, 218-222.

Blotevogel, K.-H., Fischer, U., Mocha, M. \& Jannsen, S. (1985). Methanobacterium thermoalcaliphilum sp. nov., a new moderately alkaliphilic and thermophilic autotrophic methanogen. Arch Microbiol 142, 211-217.

Boone, D. R. \& Maestrojuan, G. M. (1993). The methanogens. In Bergey's Manual of Determinative Bacteriology, pp. 719-736. Edited by J. G. Holt, N. R. Krieg, P. H. A. Sneath, J. T. Staley \& S. T. Williams. Baltimore: Williams \& Wilkins.

Boone, D. R., Whitman, W. B. \& Rouvière, P. (1993). Diversity and taxonomy of methanogens. In Methanogenesis: Ecology, Physiology, Biochemistry \& Genetics, pp. 35-80. Edited by J. G. Ferry. New York: Chapman \& Hall.
Brandis, A., Thauer, R. K. \& Stetter, K. O. (1981). Relatedness of strains $\Delta \mathrm{H}$ and Marburg of Methanobacterium thermoautotrophicum. Zentbl Bakteriol Hyg 1 Abt Orig C 2, 311-317.

Butsch, B. M. \& Bachofen, R. (1981). Temperature studies on methanogenic bacteria in Icelandic hot springs. Res Inst Nedri As Hveragerdi Iceland Rep 36, 21-42.

Ciulla, R., Clougherty, C., Belay, N., Krishnan, S., Zhou, C., Byrd, D. \& Roberts, M. F. (1994). Halotolerance of Methanobacterium thermoautotrophicum $\Delta \mathrm{H}$ and Marburg. J Bacteriol 176, 3177-3187.

Conway de Macario, E., Macario, A. J. L. \& Wolin, M. J. (1982). Specific antisera and immunological procedures for characterization of methanogenic bacteria. J Bacteriol 149, 320-328.

Fox, G. E., Magrum, L. J., Balch, W. E., Wolfe, R. S. \& Woese, C. R. (1977). Classification of methanogenic bacteria by 16S rRNA characterization. Proc Natl Acad Sci USA 74, 4537-4541.

Jarrell, K. F., Faguy, D., Hebert, A. M. \& Kalmokoff, M. L. (1992). A general method of isolating high molecular weight DNA from methanogenic Archaea (Archaebacteria). Can J Microbiol 38, 65-68.

Jordan, M., Meile, L. \& Leisinger, T. (1989). Organization of Methanobacterium thermoautotrophicum bacteriophage $\Psi \mathrm{M} 1$ DNA. Mol Gen Genet 220, 161-164.

Keswani, J., Orkand, S., Premachandran, U., Mandelco, L., Franklin, M. J. \& Whitman, W. B. (1996). Phylogeny and taxonomy of mesophilic Methanococcus spp. and comparison of rRNA, DNA hybridization, and phenotypic methods. Int $J$ Syst Bacteriol 46, 727-735.

König, H., Semmler, R., Lerp, C. \& Winter, J. (1985). Evidence for the occurrence of autolytic enzymes in Methanobacterium wolfei. Arch Microbiol 141, 177-180.

Kotelnikova, S. V., Obraztsova, A. Y., Blotevogel, K.-H. \& Popov, I. N. (1993a). Taxonomic analysis of thermophilic strains of the genus Methanobacterium: reclassification of Methanobacterium thermoalcaliphilum as a synonym of Methanobacterium thermoautotrophicum. Int J Syst Bacteriol 43, 591-596.

Kotelnikova, S. V., Obraztsova, A. Y., Gongadze, G. M. \& Laurinavichius, K. S. (1993b). Methanobacterium thermoflexum sp. nov. and Methanobacterium defluvii sp. nov., thermophilic rod-shaped methanogens isolated from anaerobic digester sludge. Syst Appl Microbiol 16, 427-435.

Laurinavichyus, K. S., Kotelnikova, S. V. \& Obraztsova, A. Y. (1988). New species of thermophilic methane-producing bacteria, Methanobacterium thermophilum. Mikrobiologiya 57, 1035-1041 [English translation: Microbiology 57 (1989), 832-838].

Macario, A. J. L. \& Conway de Macario, E. (1983). Antigenic fingerprinting of methanogenic bacteria with polyclonal antibody probes. Syst Appl Microbiol 4, 451-458.

Macario, A. J. L. \& Conway de Macario, E. (1985). Monoclonal antibodies of predefined molecular specificity for identification and classification of methanogens and for probing their ecologic niches. In Monoclonal Antibodies Against Bacteria, pp. 213-247. Edited by A. J. L. Macario \& E. Conway de Macario. San Diego: Academic Press.

Nölling, J. \& Reeve, J. N. (1997). Growth- and substratedependent transcription of the formate dehydrogenase $(f d h C A B)$ operon in Methanobacterium thermoformicicum Z245. J Bacteriol 179, 899-908.

Nölling, J., Frijlink, M. \& de Vos, W. M. (1991). Isolation and characterization of plasmids from different strains of Methanobacterium thermoformicicum. J Gen Microbiol 137, 1981-1986. 
Nölling, J., van Eeden, F. J. M., Eggen, R. I. L. \& de Vos, W. M. (1992). Modular organization of related archaeal plasmids encoding different restriction-modification systems in Methanobacterium thermoformicicum. Nucleic Acids Res 20, 6501-6507.

Nölling, J., Groffen, A. \& de Vos, W. M. (1993a). $\Phi F 1$ and $\Phi F 3$, two novel virulent, archaeal phages infecting different thermophilic strains of the genus Methanobacterium. J Gen Microbiol 139, 2511-2516.

Nölling, J., Hahn, D., Ludwig, W. \& de Vos, W. M. (1993b). Phylogenetic analysis of thermophilic Methanobacterium sp.: evidence for a formate-utilizing ancestor. Syst Appl Microbiol 16, 208-215.

Nölling, J., van Eeden, F. J. M. \& de Vos, W. M. (1993c). Distribution and characterization of plasmid-related sequences in the chromosomal DNA of different thermophilic Methanobacterium strains. Mol Gen Genet 240, 81-91.

Ostergaard, L., Larsen, N., Leffers, H., Kjems, J. \& Garrett, R. (1987). A rRNA operon and its flanking region from the archaebacterium Methanobacterium thermoautotrophicum, Marburg strain: transcription signals, RNA structure and evolutionary implications. Syst Appl Microbiol 7, 199-209.

Perski, H.-J., Moll, J. \& Thauer, R. K. (1981). Sodium dependence of growth and methane formation in Methanobacterium thermoautotrophicum. Arch Microbiol 130, 319-321.

Pfister, P., Wasserfallen, A., Stettler, R. \& Leisinger, T. (1998). Molecular analysis of Methanobacterium phage $\Psi \mathrm{M} 2 . \mathrm{Mol}$ Microbiol 30, 233-244.

Prévot, A.-R. (1980). Nouvel essai de classification des bactéries méthanogènes. CR Acad Sci 290, 1253-1255.

Schönheit, P., Moll, J. \& Thauer, R. K. (1979). Nickel, cobalt, and molybdenum requirement for growth of Methanobacterium thermoautotrophicum. Arch Microbiol 123, 105-107.

Schönheit, P., Moll, J. \& Thauer, R. K. (1980). Growth parameters $\left(\mathrm{K}_{\mathrm{s}}, \mu_{\max }, \mathrm{Y}_{\mathrm{s}}\right)$ of Methanobacterium thermoautotrophicum. Arch Microbiol 127, 59-65.
Stackebrandt, E. \& Goebel, B. M. (1994). Taxonomic note: a place for DNA-DNA reassociation and 16S rRNA sequence analysis in the present species definition in bacteriology. Int $J$ Syst Bacteriol 44, 846-849.

Stettler, R., Pfister, P. \& Leisinger, T. (1994). Characterization of a plasmid carried by Methanobacterium thermoautotrophicum $\mathrm{ZH} 3$, a methanogen closely related to Methanobacterium thermoautotrophicum Marburg. Syst Appl Microbiol 17, 484-491.

Stettler, R., Thurner, C., Stax, D., Meile, L. \& Leisinger, T. (1995). Evidence for a defective prophage on the chromosome of Methanobacterium wolfei. FEMS Microbiol Lett 132, 85-89.

Touzel, J.-P., Conway de Macario, E., Nölling, J., de Vos, W. M., Zhilina, T. \& Lysenko, A. M. (1992). DNA relatedness among some thermophilic members of the genus Methanobacterium: emendation of the species Methanobacterium thermoautotrophicum and rejection of Methanobacterium thermoformicicum as a synonym of Methanobacterium thermoautotrophicum. Int J Syst Bacteriol 42, 408-411.

Winter, J., Lerp, C., Zabel, H.-P., Wildenauer, F. X., König, H. \& Schindler, F. (1984). Methanobacterium wolfei sp. nov., a new tungsten-requiring, thermophilic, autotrophic methanogen. Syst Appl Microbiol 5, 457-466.

Yanisch-Perron, C., Vieira, J. \& Messing, J. (1985). Improved M13 phage cloning vectors and host strains: nucleotide sequences of the M13mp18 and pUC19 vectors. Gene 33, 103-119.

Zeikus, J. G. (1972). Methanobacterium thermoautotrophicus should be Methanobacterium thermoautotrophicum. Int J Syst Bacteriol 22, 395.

Zeikus, J. G. \& Wolfe, R. S. (1972). Methanobacterium thermoautotrophicus sp. n., an anaerobic, autotrophic, extreme thermophile. J Bacteriol 109, 707-713.

Zhilina, T. N. \& Ilarionov, S. A. (1984). Isolation and comparative characteristics of methanogenic bacteria assimilating formate with the description of Methanobacterium thermoformicicum $\mathrm{sp}$. nov. Mikrobiologiya 53, 785-790 [English translation: Microbiology 53 (1985), 647-651]. 